Estudios Románicos, Volumen 27, 2018, pp. 87-98

ISSN: 0210-491

eISSN: 1989-614X

DOI: https://doi.org/10.6018/ER/346561

\title{
LA CULTURA FRANCESA EN LA NOVELÍSTICA DE CARMEN DE BURGOS
}

(French Culture in Carmen de Burgos's Narrative)

\section{Carmen María Pujante Segura* \\ Universidad de Murcia}

\begin{abstract}
This article examines the representation of French culture in the work of Carmen de Burgos. The analysis of her fictional work demonstrates that her European journey of 1905 to both France and Italy had transcendental influence on the author's life and work. The publication of the epistolary travel journal Por Europa (Impresiones)/Throughout Europe (Impressions) is a defining moment in her work, since it signals a shift from translations and essays (prior to 1905) to an increasing production of short fiction, published in mass-produced weekly pamphlets, which had its boom in the early twentieth century. Many of her short stories had characters, environments and plots depicting French culture, customs, ideas, monuments and, above all, women.
\end{abstract}

Key Words: Carmen de Burgos; Fiction, Narrative; Travel; Short Story; France.

Resumen: En el siguiente trabajo se pretenden rastrear aquellas alusiones y referencias a la cultura francesa que la escritora Carmen de Burgos "Colombine" constantemente incluye en sus obras. Con el análisis de su novelística podremos demostrar que su viaje en tren a Francia -y después a Italia- realizado en el año 1905 resultó trascendental para su vida, pero también para su obra: si antes de ese año la escritora se dedicó en especial a la traducción y el ensayo, tras la publicación en 1906 de Por Europa (Impresiones), un diario de viajes escrito de forma epistolar y de estilo impresionista, se acrecienta su literatura de ficción, sobre todo de novelas cortas, publicadas en el medio de las colecciones populares que vive su auge en el primer tercio del siglo XX. En sus numerosas novelas cortas no resulta extraño encontrar personajes, ambientes y tramas en relación con Francia, su cultura, sus costumbres, sus ideas, sus monumentos, y también sus mujeres.

Palabras clave: Carmen de Burgos; Ficción; Narrativa; Viaje; Novela corta; Francia.

${ }^{*}$ Dirección para correspondencia: Carmen M. ${ }^{a}$ Pujante Segura. Facultad de Letras. Campus de La Merced. 30001 Murcia (carmenpujante@um.es). 
Confieso que al salir de Madrid no he sentido la tristeza de dejar la patria. Hoy las fronteras se conservan para la vida política de las naciones; pero el espíritu que nos anima es cosmopolita, las facilidades de los viajes, la difusión rápida de las noticias telegráficas por medio de la prensa y lo universal de las obras literarias, forman esta hermosa fraternidad que nos hace encontrarnos en los países extranjeros tan á gusto como en aquel donde nacimos. (Burgos 1906: 9)

He aquí una de las confesiones que Carmen de Burgos hace en su diario de viaje titulado Por Europa (Impresiones), publicado en 1906. Como trasluce ese fragmento, la escritora se valdrá de un tono personal, entre confesional e impresionista, para plasmar el viaje en tren que la llevará de Madrid a Francia e Italia, un viaje que emprenderá, pues, sin melancolías ni ataduras, movida por el espíritu cosmopolita del momento y también por las modernidades del transporte y de los medios de comunicación allá por los primeros años del siglo XX. Por estos y otros detalles, podrá extrañar que haya transcurrido apenas un siglo desde que Carmen de Burgos escribiera ese libro de viaje que nos va a permitir trazar puentes con otros de sus escritos, los de ficción. En no pocos de sus relatos ficcionales -algunos de los cuales serán comentados a continuación-se hallan comentarios, descripciones y retratos que reflejan la cultura extranjera, especialmente la francesa. No obstante, las alusiones a Francia son abundantísimas en la novelística de Carmen de Burgos, tanto antes como después de ese viaje. Para entender los ecos existentes entre su variada obra se hacen necesarias unas pinceladas sobre la historia y sobre la autora, que vivió en y de la literatura.

La de España y Francia es la historia de una incesante interpenetración, aunque la segunda mitad del siglo XIX represente el declinar o recul de la influencia francesa sobre España, como afirma Témime dentro de un estudio de conjunto sobre las relaciones existentes entre ambos países hasta siglo XX (En Étienvre y Urquijo 1989). Los contactos se deben a la historia, al arte, a los viajes, a la prensa y también a las guerras, pues el siglo XX no deja de ser un siglo de guerras, de dos guerras mundiales y de una Guerra Civil en España. Pero desgraciadamente detonan otras guerras, como la del Rif, de la que informa Carmen de Burgos como primera mujer corresponsal de guerra. También en este caso "Colombine" opta por plasmar el relato de la guerra, no sólo en la prensa de actualidad como corresponsal del Heraldo de Madrid, sino en la ficción, como hace en la novela corta titulada En la guerra. Episodios de Melilla, publicada en la colección de El Cuento Semanal en 1909 -es más, los propios relatos breves publicados en estos medios literarios populares también supusieron mediaciones entre España y Francia a principios del siglo XX (Pujante Segura 2012), y los trasvases entre las crónicas de guerra y las novela cortas del momento no fueron raros, incluyendo las obras escritas por mujeres (López Alcón 2014)-. ${ }^{1}$

1 De ese relato de Carmen de Burgos podemos adelantar algunas coincidencias con otros posteriores que analizaremos: en él la autora se posiciona y vierte cierto afán objetivo, documental, social e histórico, además de una considerable sustancia descriptiva centrada en el mundo militar, la cultura árabe y el paisaje, en detrimento del diálogo, de la acción y de la trama puramente ficticia. En la línea de otras obras de la autora, la historia ficcional se reserva para una historia de amor que aparece como telón de fondo en las diferentes partes del relato hasta que aflora con más fuerza al final, cuando también se explicita su interpretación, claramente antibelicista. Como también sucede en otros relatos, incluyendo los de autores contemporáneos, inmersos en los debates de la época, 
Las relaciones entre Francia y España, pues, han sido tan incesantes como los estudios y reflexiones sobre ellas y sobre sus representaciones artísticas o simbólicas. La historia de Francia ha llegado a representarte como un modelo y como una amenaza al mismo tiempo., sobre todo en textos españoles de carácter no ficcional, frente a la historia de España, que ha sido vista como una fascinación, reflejada sobre todo en obras francesas de carácter ficcional (Boixareu y Lefere 2002, 2009). En palabras de Díaz-Plaja (1970), aparte de los siete pecados capitales, Francia ante España representa la modernidad. De todo ello la obra integral de Carmen de Burgos ofrece un excelente ejemplo de lectura y de estudio: sabemos que la autora alternó bien la ficción y la no ficción y en ambos campos plasmó su mirada hacia el "otro" extranjero. En efecto, como se verá, en consonancia con esos tiempos cosmopolitas verá en Francia un país modélico, especialmente por su modernidad social, pero no podrá evitar mantener una posición ambivalente, pues no dejará de ver otros tantos aspectos que considera negativos.

Pero, además, Francia representa un modelo, el modelo cosmopolita, y un intermediario necesario, como se aprecia en ese contexto de entre-siglos a través de diferentes movimientos literarios y sociales: "Presque tous les mouvements d'idées, sauf, il est vrai, le krausisme, viennent de France. Lorsque celle-ci n'est pas le modèle à imiter, elle reste l'intermédiaire nécessaire. [...] La France symbolise donc, en Espagne, la culture occidentale, voire cosmopolite" (Aubert 1989: 66). Se está en el contexto del Naturalismo de Zola, que también llega a España, con todas sus particularidades filtradas especialmente a través de Emilia Pardo Bazán (Baquero Goyanes 1955); del modernismo, de un particular erotismo y del exotismo (Litvak 1975, 1979, 1986); de un feminismo y un cosmopolitismo de época (Rivalan Guégo 2005, 2008); de multitud de imágenes y estereotipos entre ambos países (Lafarga 1989). Todo ello se aprecia y se siente en el mundo de las novelas cortas del primer tercio del siglo XX (Martínez Arnaldos 1975), un mundo que bien representaba Carmen de Burgos (Sánchez Álvarez-Insúa 2010), con sus lecturas de Pardo Bazán y Blasco Ibáñez, con sus imágenes de la mujer y su feminismo (Establier 2000), sus múltiples modernidades (Louis y Sharp 2017), sus traducciones (Simón Palmer 2010) o sus propios libros de viajes, donde también plasma sus ideas sobre el debate de la educación y la situación de la mujer (Daganzo 2010). ${ }^{2}$

No obstante, este crisol se aprecia igualmente en la obra de otras escritoras contemporáneas a Carmen de Burgos, autoras de relatos cortos o nouvelles, tales como Sofía Casanova o Elsa Triolet, entre otras de la primera mitad del siglo XX (Pujante Segura 2014). No pocas aportaciones contribuyen a dibujar el rico contexto intersticial entre el siglo XIX y XX, pero sólo se añadirán algunas pertenecientes a personalidades destacadas como la de Concepción Arenal quien, en Estado actual de la mujer en España de

se alude a la cuestión de la raza, aunque en el caso de Carmen de Burgos no se desaprovecha para poner la mirada en la situación de la mujer; dentro de En la guerra, se llegará a decir, por ejemplo, que "parecía que en Melilla cristianos, moros y judíos rivalizaban en ocultar a sus hembras" (1909: 14).

2 "En esta literatura, el retrato de las mujeres españolas se hace de forma contrastada, comparándolas frecuentemente con las mujeres francesas. A veces es la misma heroína la que lleva el peso de la opresión social española al mirar fuera de las fronteras. Sin embargo Francia, tierra mítica de libertad para las mujeres, sobre todo en esta literatura, también lucha para que las ideas nuevas avancen. Y, del mismo modo que en España, entre las firmas de las novelas militantes encontramos a los grandes nombres de las colecciones populares" (Rivalan 2008: 109). 
1895, confirmaba que entre las disciplinas que se impartían a la mujer estaba el francés. Pero la mujer, al fin y al cabo, estaba abocada a ser madre. La propia Carmen de Burgos en Quiero vivir mi vida, aludiendo a la maternidad, no podía evitar la comparación con el país francés: " ¡Siempre la maternidad! Es el baluarte que les queda a las insignificantes. Pero es cosa más extendida de lo que crees. Ya ves ahora en Francia. Es un país donde las mujeres tienen fama de maternales... y todos han estado a favor de esa dama inglesa que le dio un tiro a la esposa de su amante porque él no se quería divorciar para casarse con ella" (1931: 231).

Su biógrafa, C. Núñez Rey (2005), ya ha ofrecido un balance de su "novelesca vida": Carmen de Burgos se lanzó de Almería al mundo y lo plasmó en una variada obra, que incluye ficción y no ficción y que tiene como soporte innegable la literatura de kiosco, en boga en su momento gracias a la estela abierta por la colección de El Cuento Semanal desde 1907 (se ha de saber que en uno de sus primeros números la dirección de la publicación ya explicitaba sus objetivos: trasplantar en España el mismo éxito del que habían gozado estas ediciones de nouvelles en Francia). Ese mundo editorial le permitió contar con un sueldo, igual que las traducciones: aunque no llegara a ser traducida en ese momento, ejerció como traductora, también de obras francesas, si bien en no pocos casos la traducción no era directa. De entre sus referentes, se ha de aludir a Nordau con sus ideas en torno al socialismo y el sionismo, a quien conoció en las tertulias de París en 1905; o incluso la Ligue du Droit des Femmes, que luchaba por la defensa del sufragio femenino y la educación laica. También son referentes en ese contexto E. Pardo Bazán, C. Campoamor o C. Arenal. ${ }^{3}$

La visión de la cultura francesa de Carmen de Burgos se explica a la luz de todo ese crisol y se refleja en su ficción novelística, como se puede prever, de una manera compleja y rica, pues los ecos de Francia llegaban a España por una inmensidad de direcciones que hacían que ante la influencia nadie pudiera permanecer impasible, ciego o sordo. Así pues, podemos releer y analizar una selección de sus obras, siguiendo aquí un orden cronológico con el objetivo de atisbar cierta evolución de su pensamiento socio-literario. Se pueden rastrear testimonios antes y después de su obra Por Europa (Impresiones), es decir, antes y después del año 1906, el de ese viaje emprendido en tren por Francia y luego por Italia. Sin poder ser exhaustivos, podemos hallar alusiones a la cultura francesa por ejemplo en El veneno del arte de 1910, en La indecisa de 1912, en El perseguidor de 1917, en El permisionario de 1917, en La entrometida de 1921, en La tornadiza de 1923, en La melena de la discordia de 1925 o en ;La piscina! ;La piscina! de 1930.

\footnotetext{
3 Sin duda, el horizonte de los referentes posee un valor muchas veces descuidado. La periodista Rosa M. ${ }^{a}$ Calaf, en su conferencia sobre Carmen de Burgos, organizada por la Biblioteca Nacional de España en noviembre de 2017 junto a Concepción Núñez Rey, admitía que nadie le había hablado de Carmen de Burgos durante sus estudios de Periodismo. En ese homenaje, la especialista Núñez Rey también destacó que Carmen de Burgos realizó su viaje a Francia en busca de "modelos femeninos europeos para verterlos en España"; además, en ese momento empieza a escribir "por lo que ve", no a partir de lo que lee. Por todo ello, el viaje plasmado en Por Europa supuso una "revolución" en la vida de Carmen de Burgos, pues además fue entonces cuando se volvió "más revolucionaria" (sin que dejara de ser más "regeneracionista" que revolucionaria). Núñez Rey se ha encargado asimismo de la edición de Mis viajes por Europa: Suiza, Dinamarca, Noruega, Alemania, Inglaterra, Portugal (Madrid, Los Libros de la Catarata, 2012), por lo que queda por asumir la edición del libro de viajes Por Europa (Impresiones), centrado en Francia e Italia, y hoy de de difícil acceso.
} 
Ciertamente, se ha de partir de la relevancia de la publicación de Por Europa (Impresiones), en Maucci, una colección que publica sobre viajes. Esa obra de Carmen de Burgos se sitúa entre lo epistolar y lo diarístico (la primera parte la escribe desde Francia, mientras que la segunda y la tercera lo hace desde Italia), plasmando un estilo "impresionista" (desde la subjetividad, con preguntas retóricas, numerosos adjetivos, etc.). Está dedicado a Ferrandiz y datado: primero en Hendaya, el 6 de octubre de 1905, siendo la tercera carta la que ya redacta en París, en el marco del "Congreso contra la tuberculosis". Aparece ilustrado con fotos, por ejemplo de El Escorial (la primera), el león de la República Francesa (la segunda), Biarritz, Bayona, etc. Refleja el trayecto en tren hasta París para pasar a aludir a la ciudad, el arte, personalidades conocidas o la religión, incluyendo recuerdos y comparaciones (por ejemplo, respecto a la vida de sus padres o con las mujeres -reinas, personajes femeninos de Maupassant, etc.-, incluyendo la forma de vestir). Así pues, la primera parte se estructura así: parte de las secciones De Madrid a la frontera y De Hendaya á París, pasando por Conquistas de la ciencia, Por las calles de París, Cuadros de París, París de noche, Los Museos, Los teatros, La Pintura, Max Nordau, La Ciudad de la Muerte, El Palacio de Castilla, Las Iglesias, La Morgue, Alfredo Nasquet y Jean Jaurés, Los Anarquistas, De París a Niza, La ciudad encantada, Paganini, El Castillo, hasta llegar a las partes dedicadas a Mónaco y Montecarlo.

Antes de esta obra, Carmen de Burgos se había dedicado sobre todo al campo de la traducción y del ensayo. Gracias a sus contactos con el mundo de la prensa, consigue realizar este viaje en 1905, el cual es anunciado por El Heraldo (tal era la consideración de la escritora), pero resulta sumamente significativo que sea a partir de esa fecha cuando Colombine se entregue al mundo de la ficción, especialmente el de sus cuantiosas novelas cortas. De ese diario de viaje podemos destacar algunos pasajes, relevantes por sus ecos en la ficción posterior. Por ejemplo, en la cuarta carta, al comienzo y antes de ofrecer su impresión, afirma que "[u]na descripción de París es de las cosas más difíciles que puedan pedírsele al ingenio humano. Todos los que lo intentaron han sido poco afortunados, excepto el inmortal Zola": recordemos su admiración por este escritor así como por su introductora en España, Pardo Bazán, con todo lo que supone el naturalismo en la literatura española en el tránsito al siglo XX; además, esa mención viene a traslucir que la primera "impresión" que Carmen de Burgos poseyó de la capital francesa no podía no ser estrictamente literaria, de modo que sus primeros posicionamientos no se deben a su testimonio in praesentia. Más adelante, en el cierre de la sexta carta ofrece estas significativas palabras, con las que compara ambas naciones y muestra su amor patriótico: "Por mi parte cuanto más veo á Francia más amo á nuestra tierra; no se me ocultan sus defectos, pero al lado de la civilización francesa comprendo mejor sus virtudes" (1916: 60). Efectivamente, con sus viajes sí habrá agravio comparativo, pues en sus comparaciones acabará ganando su país. Más adelante, en la decimoséptima carta escribe sobre Niza, ciudad que prefiere pues sigue el ideal de Rousseau, el que valora el mar y la Naturaleza, precisamente los elementos que le recuerdan a su tierra, tal y como ella afirma (de nuevo, el primer filtro para la autora es el de sus lecturas previas al viaje). No menos curiosas son las impresiones sobre Italia, que también le sirven para trazar comparaciones con España (lo cual ha de ser el objetivo de otro estudio que promete ser fructífero). Finalmente, en 
su regreso pasando por Barcelona, Carmen de Burgos escribirá sobre "el fantasma de Cataluña" , a la que compara con Suiza para mostrarse contraria a la centralización estatal en términos generales. Y por fin llega a Almería, su "patria chica", y lo hace como un Don Quijote por los campos de Montiel: así se siente la escritora después de ese periplo.

Como se ha adelantado, resulta inexcusable la consideración de esos apuntes epistolares y viajeros para su comparación con la narrativa de la autora, especialmente con sus novelas cortas. En la indispensable antología de novelas cortas de la escritora, ${ }^{5}$ Núñez Rey alude a un relato epistolar como es El novenario, uno de sus experimentos de Carmen de Burgos que está en consonancia con el laboratorio que supuso el género de la novela corta en las primeras décadas del siglo XX en España. Igualmente se refiere a novelas "de viajes", en las que hay espacios concretos, una mirada sobre los detalles, ambientes recreados, un reflejo de la Europa contemporánea, además del reflejo de su querencia por Portugal y Francia. Como en su relato de viajes, la autora no puede evitar trazar comparaciones a través de la figura de la mujer; a ese respecto su estudiosa afirma: "la que horroriza a la autora es la mujer símbolo de la España negra y tradicional, la que envejece «rezando y tomando pectorales»; junto a ésta, teme la posibilidad de la mujer víctima del hombre y de la sociedad: antes que ellas prefiere y propone a una frívola, coqueta y superficial" (Núñez Rey 1989: 47). Así pues, la permeable frontera existente entre los textos ficcionales y no ficcionales de Carmen de Burgos ha de imponerse en éste y otros estudios sobre su obra en pos de su comprensión contextualizada y profunda y de la rigurosidad analítica e interdiscursiva.

Nos adentramos, pues, en su ficción, la escrita después del viaje a Francia e Italia. En El veneno del arte (publicada originalmente en Los Contemporáneos en 1910) aparece una escritora feminista que frecuenta las reuniones en el salón-despacho de Luis de Lara: él es "de espíritu artista y bohemio", mientras que ella es de origen noble, sobre lo cual se muestra cierta sátira (por ejemplo, al hablar de ella como "Emperatriz de las cursis"). En ello no se desmarca de otras obras del momento, ni ajenas ni propias; de hecho, se encuentran rasgos en algunos personajes que resultan muy similares a los de otras obras de Carmen de Burgos, como el de Lolita en La entrometida -que después se analizará- o incluso la alusión a la "maja" de Goya, que retomará en su novela corta supuestamente erótica titulada La que quiso ser maja (y es que el de Carmen de Burgos "Colombine" fue de los pocos nombres femeninos que llegaron a aparecer entre las colaboraciones en colecciones de novelas cortas supuestamente eróticas, lo cual resulta una vez más revelador de la importancia y peculiaridad de la escritora que estudiamos; recordemos, asimismo,

$4 \quad$ Es curioso también este testimonio suyo presente en esas impresiones viajeras de 1906: "No me asusta ya el fantasma de Cataluña después de venir de Suiza. Aquella autonomía de los Estados federados con vida propia, lenguas diferentes y costumbres y leyes apropiados á sus necesidades, no desmembran [sic] la patria [...]. Toda centralización y hegemonía es antipática [...].” (Burgos 1916: 497)

5 Es de justicia aludir a la antología de 1990 a cargo de A. Ena Bordonada, Novelas breves de escritoras españolas (1900-1936), así como el estudio de R. C. Imboden sobre la novela corta de Carmen de Burgos en el año 2000. No obstante, la actualización de los estudios sobre Carmen de Burgos "Colombine" se puede encontrar en la edición de las Novelas del Ciclo de Rodalquilar, publicada en 2017 también por Núñez Rey; de esa manera, lamentamos tener que obviar otras importantes referencias bibliográficas actualizadas sobre la escritora. Así se está contribuyendo a esclarecer esta parte de la historia de la literatura española. 
la alusión de Díaz-Plaja a los pecados capitales, incluyendo el de la lascivia, que podrían representar Francia ante España). También hay alusiones a autoras como Safo, Teresa de Jesús, Agustina de Aragón, etc., lo cual vendría a confirmar lo atisbado anteriormente: los referentes de Carmen de Burgos son especialmente los literarios, también para los modelos de mujer que perfila, aunque en este caso no incluya ninguna mención a autoras o protagonistas francesas. Asimismo, como en tantos otros relatos de escritores contemporáneos, la influencia se aprecia en el estilo de la escritura, pues vuelven a ser frecuentes los galicismos y los extranjerismos en general (por ejemplo, cuando se dice lo siguiente: "En un ángulo del salón, un jovencito taciturno epataba a un círculo de contertulios, con una erudición de enciclopedia barata"; o cuando aparece un hombre que cayó enamorado de la hija de la marquesa cuando la vio hacer la toilette). Por otra parte, los personajes representan estereotipos, presentados entre ironía y parodia, y además, recurriendo a alusiones a algún aspecto francés: los luchadores de Madrid son los pobres que se creen superiores por ser conocidos, como pueden ser algunos críticos, por ejemplo, los que censuran a Zola o Blasco Ibáñez (de nuevo, aparecen los referentes literarios); un novelista sicalíptico: "ansioso de estudiar las raras psicologías de las decadentes para sus novelas, escritas en jerga semi-francesa"(por lo que la imitación del francés se plasma tanto en la forma de hablar como en la de escribir); "jovencitos dulces, femeninos, soñadores", que llevan 'nombre de guerra', como La Manon (seguramente inspirándose en Manon Lescaut de Prévost y en la posterior ópera de Puccini, aunque sea para parodiar, en este caso, con un apodo para un hombre homosexual); y pocas mujeres, normalmente rivales, como la Marquesa de la Charca, además de extranjeras (como es el caso de una americana que aparece en este relato). Retrata todo ello la escena en que el protagonista, Luis, se encuentra triste y suspirando: “ $\mathrm{OOh}$, París!”. Y es que la ciudad francesa le trae unos buenos recuerdos que le hacen sentirse melancólico y nostálgico en España: con ese suspiro no menos paródico, se hace presente el decadentismo finisecular que veía en el país francés la cuna de los poetas malditos.

En otra novela corta, La indecisa (publicada en El Libro Popular en el año 1912), Alina, tras una historia de amor fracasada con Adolfo, se va a París: así aparece la ciudad como un espacio liberador para la mujer, que decide emprender un viaje (lo cual no puede no recordarnos la situación de la escritora en el momento de redactar su libro de viajes). Por su parte, en El perseguidor (aparecida en La Novela Corta en 1917) se relata una historia que comienza en Nochebuena, momento en que se presenta a la protagonista, Matilde, que se siente nostálgica: está recordando "escenas patriarcales de su vida española". Para escapar, "se casó con el primer señorito de Córdoba que la requirió en amores y que le habló de vivir en Madrid", pero se queda "libre" y viaja, pues enviuda a los tres meses:

Entonces se despertó en ella el amor a los viajes de un modo avasallador [...]. Aquella afición a los viajes le había abierto nuevos cauces de pensamiento y había educado su sensibilidad; disgustándola de todas las costumbres de la vida vulgar. Viajaba constantemente, buscando nuevas impresiones. ("El perseguidor", Burgos 1917: 7) 
Nótese la alusión a las "impresiones" y al "amor a los viajes", en relación con su diario de viajes. Pero ese relato imaginado continúa: la protagonista llega a Venecia, donde reflexiona sobre las mujeres y donde encuentra a Daniel, "el perseguidor", el que justamente da título a la obra. Pero en su afán de viajar llegará también a Nápoles (en la segunda parte, donde justamente se incluyen cartas), a Suiza, a Noruega, a Copenhague y a Londres, volviendo a Castilla (en el séptimo capítulo), para entonces percatarnos de que todo ha sido un sueño. Y es que, no lo olvidemos, Carmen de Burgos emprendería otro viaje más adelante que la llevaría a los países nórdicos. Pero nótese el rasgo recurrente o "tic" de la escritora que plasma también en sus obras de ficción: cualquier situación o persona es válida para establecer una comparación entre España y el extranjero. Además, se ha de destacar el estudio de Elena Lindholm sobre esta obra, "Putting the brake on Matilde. The woman traveller in Carmen de Burgos's El perseguidor" (2017: 109-126), en el que pone el foco sobre la mujer viajera a la que se le debe "poner freno", pues por cuestiones de su género a la mujer moderna se le aparecen esos "fantasmas patriarcales" (y freudianos) que son los acosadores y sus voces de prohibición, aunque su historia acabe con un "happy ending". ${ }^{6}$

Es en otra novela corta publicada en 1917 en Los Contemporáneos donde se encuentran más alusiones. El comienzo de El permisionario dice así: "Después de tantos meses iban a volverse a ver. Era aquella una verdadera cita de novios, de enamorados, que se habían dado en Niza para gozar mejor del descanso en un clima dulce en medio de los encantos de una naturaleza bienhechora”. Recordemos que Carmen de Burgos en su libro de viajes ya confesaba su debilidad por la ciudad de Niza. En esta novela corta se trata la historia de Luis y Fernanda, una historia de amor en la guerra. Para verse, ella aparece preparándose para el viaje del reencuentro: aunque, como dice la voz narradora, Fernanda ya estaba habituada al "ambiente melancólico" parisino, el viaje a Niza la pone más triste al ver a hombres mutilados y a mujeres de luto, que pueblan los trenes y las estaciones, siempre en silencio, lo que contrasta con aquel momento en el que iban a la guerra, por ejemplo, entonando La Marsellesa. En ese relato de ficción se incluye la escena de un paseo que sirve para incluir una descripción de calles y personas, incluyendo los nombres en francés, y destaca la importancia del mar. Se estructura

\footnotetext{
6 En realidad, todo este análisis de la cultura francesa en la novelística de Carmen de Burgos se vería iluminado por las múltiples modernidades de la figura de Carmen de Burgos que sacan a la luz Louis y Sharp (2017) en el volumen que editan y al que contribuyen numerosos especialistas: también en la representación de lo francés en la obra de la autora se han de considerar a un tiempo sus facetas tanto de escritora como de activista, facetas que un día se perdieron de vista y que recientemente se están poniendo en valor (como plantea E. Starcevic); en todo ello no han podido no influir algunos episodios vitales tales como su separación matrimonial como su activismo político, aunque algunos enigmas en torno a ello permanezcan (según M. Bieder); así, se ha de situar a Carmen de Burgos en la genealogía del pensamiento feminista español (a decir de R. Johnson), en la línea de otras autoras que la influenciaron como Pardo Bazán (siguiendo a A. I. Simón Alegre) y en confluencia con autores también diferentes como Unamuno o Baroja (como estudia T. R. Franz); y se ha de plantear así en su obra no ficcional, pero también en la de ficción como en La melena de la discordia (obra analizada por K. Doyle), El perseguidor (a cargo de E. Lindholm), La entrometida (estudiada por A. Louis), Ellas y ellos o ellos y ellas y Quiero vivir mi vida (en las que profundiza L. Estrada), o La perfecta casada (estudiada por M. M. Sharp); porque buscó hablar especialmente a un público femenino (como destaca M. Ugarte), para llevar la "escuela" a la "despensa" incluso gracias a libros de cocina (estudiados por R. Ingram). Que sirva todo ello de panorámica para iluminar aunque someramente las múltiples modernidades de Carmen de Burgos.
} 
siguiendo los siete días de la semana, a lo largo de los cuales transcurre la historia que finaliza circularmente, en la estación de tren.

Pero también en otras novelas cortas aparecen referencias. En La entrometida (que también ve la luz en la colección de La Novela Corta pero en 1921) los personajes principales son los de Clarisa y de Ángela: ambas son víctimas de la indiferencia institucional y el ensañamiento, pues carecen de una formación adecuada para enfrentarse al mundo, según la interpretación de Helena Establier. ${ }^{7}$ Ángela aparece diciendo:

Yo no me conformaba con ser la solterona inútil para todo, con gesto de niña que no puede salir sola; no me avenía a pasar miseria en la inacción. No me dejaban hacer nada: todo era malo, incorrecto, deprimente; todo ponía en ridículo a mi familia. 'Mientras viva tu madre no puedes hacer eso', me repetían de continuo en las cosas más sencillas; y como yo tengo el deseo de que mi madre viva más que yo, preferí marcharme a París; he caído bien. Doy lecciones de español por método mío, tengo buenas discípulas y allí, donde no hay solteronas ni solteritas, no paso admirablemente. (Burgos 1921: s.p.)

Efectivamente, Ángela decide irse a París, mientras que Clarisa, el otro personaje, opta por Londres. Y continúan las alusiones. En la primera parte de La tornadiza (Los Contemporáneos, 1923) aparece la ciudad de París: La Cité, Notre Dame, Quai Voltaire, Rue de Rennes, Procope, etc. Igualmente se encuentran en La melena de la discordia (La Novela Semanal, 1925), en especial por el motivo que hace arrancar la trama, esa melena "a lo garçonne", con todo el despliegue de asociaciones femeninas "modernas". Hasta sus últimas novelas cortas incluyen referencias a la cultura francesa, como en iLa piscina! ¡La piscina! (La Novela de Hoy, 1930). En esa historia aparece una familia murciana, que con las hijas Isabel y Julita se muda a París, ese París, en palabras de Establier, que "se halla bien lejos de ser la ciudad romántica y dulcemente melancólica de las primeras novelas o de los libros de viajes de la autora; ahora es el escenario privilegiado de la modernidad, bullicioso, luminoso, inundado por las bocinas de los autos, los gases modernidad" (Establier 1997: 701). Por ejemplo, en la novela corta se dice lo siguiente: "La ciudad inmensa creaba algo absorbente que hacía que no se fijasen en ellas". (Pero no se puede dejar pasar esta cita de la obra: "La piscina tomaba un lugar tan importante en la vida de las iniciadas que obraba sobre ellas como la cocaína o la morfina. Esclavizaba").

Tras este repaso por la novelística de Carmen de Burgos en busca de estudiar el valor de la cultura francesa en su obra, podemos concluir que se ha de apreciar un antes y un después de su viaje por Francia (e Italia) y de la correspondiente publicación de Por Europa (Impresiones) en el año 1906. Las menciones se hallan tanto en obras de ficción como en obras ensayísticas, diarísticas o hasta periodísticas: es complejo deslindar la fusión de textos y géneros propia de la escritura de Carmen de Burgos. En los casos analizados, se trata de ficción basada en un diario de viaje en forma de carta y en artículos periodísticos. Ello tam-

$7 \quad$ Esto afirma de Ángela en su breve intervención en la cena en casa de Pérez Blanco: "El tipo que Ángela representa es una constante en la novelística de Colombine: la huérfana burguesa que se encuentra, de la noche a la mañana, en situación precaria y que se ve forzada a incorporarse al restrictivo mercado laboral español; las dificultades [...] la llevan a buscar cobijo en Francia, sociedad que se ofrece como modelo de libertad e independencia para la mujer" (Establier 1997: 405). 
bién explicaría la preeminencia de un estilo impresionista, salpicado de galicismos y otros extranjerismos (muy de la época) y del recurso del contraste, en especial para hablar de las costumbres, los paisajes y las personas. Esos contrastes se marcan en las oposiciones entre la ciudad y el pueblo, entre lo español y lo extranjero, e incluso entre la mujer ideal y otros modelos de mujeres. Todo se halla impregnado o amalgamado por la presencia inexcusable de la cultura francesa que, paradójicamente, asume valores positivos que, sin embargo, van cambiando para adquirir un cariz negativo.

Todo ello no ha podido ser entendido fuera de la contextualización de España en la historia vivida entre finales del siglo XIX y XX, período justamente en el que vivió y escribió Carmen de Burgos y que ha sido desentrañado al comienzo. Las referencias a Francia parecen ineludibles en ese ambiente, para ella y para la mayoría de los escritores y pensadores del momento: parece una inercia de los siglos la continua alusión comparativa con los franceses que llega y aun se prolonga en el siglo XX. De esa inercia no puede sustraerse Carmen de Burgos, primero como lectora y después como viajera, como escritora y como persona comprometida social y políticamente. No obstante, aun no pudiendo zafarse de la mirada hacia el "otro" francés, e incluso a la "otra" francesa, la escritora consigue gracias a sus lecturas y sus viajes ganar cierta perspectiva y lucidez: no niega el modelo positivo francés, pero lo parodia y lo critica. Es sabedora y conocedora de que más allá de España hay aspectos dignos de imitar para conseguir un mundo mejor y cierto es que Francia en ese contexto viene a representar Europa o ese mundo en general. La intención, pues, es la de ofrecer al público español -mujeres y hombres- un modelo de progreso en lo social y en lo literario, pero también la de poner en valor cierta "esencia" española, por lo que le resultan inevitables los juicios de valor, implícitos y explícitos. En su visión, tanto en las impresiones viajeras como en las obras ficticias, no consigue evitar un poso melancólico cuando está fuera. Pero se ha podido comprobar que su mirada se desvía continuamente hacia las mujeres extranjeras en general y las francesas en particular, para que las españolas tengan una referencia con la que compararse, como se suele decir, para bien y para mal. Así se aprecia un rasgo propio de Carmen de Burgos que no pudo eludir ni siquiera en sus textos periodísticos, a priori enfocados desde la objetividad: su estilo impresionista, que logra resaltar aún más gracias a la literatura, al terreno de la imaginación y la recreación. De ahí que sus tramas narrativas puedan resultar determinadas por una intención personal de la escritora y que puedan ofrecer una interpretación encaminada a un determinado público lector.

Que sirvan estas conclusiones, asimismo, para confirmar la necesidad de continuar con los estudios sobre Carmen de Burgos, por ejemplo, con análisis contrastivos entre sus textos ficcionales y no ficcionales desde perspectivas temáticas y estructurales, y para confirmar también la conveniencia de reeditar sus obras, especialmente las de viajes.

\section{BIBLIOGRAFÍA}

AUBERT, Paul (1989): "L'influence idéologique et politique de la France en Espagne de la fin du XIXe siècle à la Première Guerre mondiale (1875-1918)", en ÉTIENVRE, Jean-Pierre; URQUIJO GOITIA, José Ramón (eds.), España, Francia y la Comunidad Europea. Madrid, CSIC/Casa de Velázquez: 57-102. 
BAQUERO GOYANES, Mariano (1955): La novela naturalista española: Emilia Pardo Bazán. Murcia: Publicaciones de la Universidad de Murcia.

BOIXAREU, Mercè; LEFERE, Robin (coords.) (2002): La historia de España en la literatura francesa: una fascinación. Madrid: Castalia.

(2009): La historia de Francia en la literatura española: amenaza o modelo. Madrid: Castalia.

BURGOS, Carmen de (1906): Impresiones. Madrid: Maucci.

(1931): Quiero vivir mi vida. Madrid: Biblioteca Nueva (prólogo de Gregorio Marañón).

(1989): La flor de la playa y otras novelas cortas. Madrid: Castalia (ed. C. Núñez Rey).

(2012): Mis viajes por Europa: Suiza, Dinamarca, Noruega, Alemania, Inglaterra, Portugal. Madrid: Ediciones de la Catarata (ed. C. Núñez Rey).

DAGANZO CANTENS, Esther (2010): Carmen de Burgos: educación, viajes y feminismo (la educación y el feminismo en los libros de viajes de Carmen de Burgos a Europa). Jaén: Publicaciones de la Universidad de Jaén.

DÍAZ-PLAJA, Fernando (1970 [1969]): El francés y los siete pecados capitales. Madrid: Alianza Editorial.

ENA BORDONADA, Ángela (ed.) (1990): Novelas breves de escritoras españolas (1900-1936). Madrid: Castalia (Instituto de la Mujer).

ESTABLIER PÉREZ, Helena (1997): Mujer y feminismo en la obra de Carmen de Burgos "Colombine". Alicante (tesis doctoral): Universidad de Alicante.

ÉTIENVRE, Jean-Pierre; URQUIJO GOITIA, José Ramón (eds.) (1989): España, Francia y la Comunidad Europea (Actas del segundo coloquio hispano-francés de historia contemporánea celebrado en Aix-en-Provence los días 16, 17 y 18 de junio de 1986). Madrid, CSIC/Casa de Velázquez.

IMBODEN, Rita Catrina (2000): Carmen de Burgos "Colombine" y la novela corta. Bern: Peter Lang.

LAFARGA, Francisco (ed.) (1989): Imágenes de Francia en las letras hispánicas. Barcelona: PPU.

LINDHOLM, Elena (2017): "Putting the brake on Matilde. The woman traveller in Carmen de Burgos's El perseguidor", en LOUIS, Anja \& SHARP, Michelle (eds.): Multiple Modernities: Carmen de Burgos, Author and Activist. London \& New York: Routlege, 109-126.

LITVAK, Lily (1975): El modernismo. Madrid: Taurus.

(1979): Erotismo fin de siglo. Barcelona: Bosch.

(1986): El sendero del tigre. Exotismo en la literatura española de finales del siglo XIX (1880-1913). Madrid: Taurus.

LÓPEZ ALCÓN, Noemí (2014): "Las crónicas de Guerra y la novela corta en las primeras décadas del siglo XX", Tonos digital. N. ${ }^{\circ} 27,20$ págs.

LOUIS, Anja; SHARP, Michelle (eds.) (2017): Multiple Modernities: Carmen de Burgos, Author and Activist. London \& New York: Routlege. 
MARTÍNEZ ARNALDOS, Manuel (1975): La novela corta española en el primer tercio del siglo XX. Teoría y práctica. Murcia: Secretariado de Publicaciones e Intercambio Científico de la Universidad de Murcia.

NÚÑEZ REY, Concepción (ed.) (1989), "Introducción", en BURGOS, Carmen de: $L a$ flor de la playa y otras novelas cortas. Madrid, Castalia: 9-75.

(2005): Carmen de Burgos Colombine en la Edad de Plata de la literatura espanola. Sevilla: Fundación José Manuel Lara.

PUJANTE SEGURA, Carmen M. ${ }^{\mathrm{a}}$ (2012): "Relatos breves publicados en revistas, otras mediaciones literarias entre España y Francia en la primera mitad del siglo XX", Tonos Digital. N. ${ }^{\circ} 22$ : 1-23.

(2014): De la novela corta y la nouvelle (1900-1950). Estudio comparativo entre escritoras. Madrid: Síntesis.

RIVALAN-GUÉGO, Christine (2005): "Féminité/Féminisme: Quête de définition dans l'Espagne du début du XXe siècle", Pandora. Revue d'études hispaniques. N. ${ }^{\circ}$ 5: $73-85$.

(2008): Fruición-ficción. Novelas y novelas cortas en España (1894-1936). Gijón: Trea.

SÁNCHEZ ÁLVAREZ-INSÚA, Alberto: (2010): "Carmen de Burgos y las colecciones de novela corta". Arbor, CLXXXVI: 65-70.

SIMÓN PALMER, María del Carmen (2010): "Carmen de Burgos, traductora", Arbor., CLXXXVI: 157-168.

TÉMIME, Émile (1989), "France et Espagne dans la seconde moitié du XIXe siècle: le déclin d'une influence", en ÉTIENVRE, Jean-Pierre; URQUIJO GOITIA, José Ramón (eds.), España, Francia y la Comunidad Europea. Madrid. CSIC/ Casa de Velázquez: 247-264.

\section{PERFIL ACADÉMICO Y PROFESIONAL}

Carmen M. Pujante Segura imparte actualmente su docencia en la Universidad de Murcia en el área de Teoría de la Literatura y Literatura Comparada como Profesora Contratada Doctora. Filóloga hispánica y francesa, Premio Extraordinario de Doctorado por la Facultad de Letras de 2010-2011, ha sido investigadora de proyectos de investigación sobre análisis interdiscursivos y sobre retórica cultural, y también ha realizado estancias externas en Bélgica y Francia. Ha participado con comunicaciones y conferencias en congresos nacionales (Barcelona, Granada, Girona, Murcia, etc.) e internacionales (Bérgamo, Leuven, París, Carrolton (Georgia, EE.UU.), etc.), así como con publicaciones en revistas, a lo que se suma la coedición del último número $(19,2014)$ de la revista Monteagudo en torno a "La Primera Guerra Mundial y el acontecer literario en España: 1914" y su estudio De la novela corta y la nouvelle (1900-1950). Estudio comparativo entre escritoras (Síntesis, 2014). Ha participado en la organización de congresos internacionales como el XXV Congreso de la Asociación Hispánica de Literatura Medieval en 2011.

Fecha de recepción del artículo: 14-05-2018

Fecha de aceptación del artículo: 13-06-2018 